\title{
El debate jurídico entorno a la tensión del principio de confianza legítima y la prevalencia del interés general.
}

\section{The legal debate surrounding the tension of the principle of legitimate expectations and the prevalence of the general interest.}

\author{
Autores: Marcela Viviana León García. ${ }^{1}$ \\ Correspondencia: mleon@corsalud.edu.co - mvleon@unisimonbolivar.edu.co
}

\begin{abstract}
RESUMEN
En este artículo de reflexión se expone de manera teórica la tensión existente en el plano jurídico entre el principio de confianza legítima y el principio de prevalencia de interés general. Así pues, se analizan los diferentes criterios de interpretación que ha utilizado la Corte constitucional para su resolución, en casos tan especiales como el de ocupación del espacio público por parte de vendedores estacionarios.
\end{abstract}

\section{Palabras Clave}

Confianza legítima, Prevalencia del interés general, interpretación constitucional, vendedores estacionarios.

\begin{abstract}
In this article of reflection we will analyze on the theoretical tension between the principle of legitimate expectations and the principle of general interest prevalence. Thus, we analyze the different criteria of interpretation used by the Constitutional Court for its resolution, in cases as special as the occupation of public space by stationary sellers.
\end{abstract}

\section{Keywords}

Legitimate trust, Prevalence of general interest, constitutional interpretation, stationary sellers.

\footnotetext{
1 Abogada, Magister en Derecho Administrativo, se ha desempeñado como Coordinadora de la Red Colombiana de Semilleros de investigación RedColsi Nodo Atlántico. Docente investigador en las Universidades Simón Bolívar y Corsalud de Barranquilla.
} 


\section{Introducción.}

Sea preciso partir con una conceptualización de la expresión confianza, que nos permita entender desde el sentido común el tema que se va a abordar. En este orden de ideas, de acuerdo con el Diccionario de la real Academia Española, el vocablo "Confianza" representa en sí mismo la "Esperanza firme que se tiene de alguien o algo". Este concepto viene del verbo "confiar", que en sus diferentes acepciones significa "Encargar o poner al cuidado de alguien algún negocio u otra cosa; depositar en alguien, sin más seguridad que la buena fe y la opinión que de él se tiene, la hacienda, el secreto o cualquier otra cosa". Pero la acepción que más interesa en el contexto de este trabajo es la que establece que confianza significa "esperar con firmeza y seguridad". Por fuera de toda referencia teológica, esta noción permanece estrechamente ligada a la idea de creer en la palabra de otro y de esperar que los poderes superiores no sean ejercidos en nuestro detrimento.

La palabra "confianza", desde el punto de vista etimológico, viene del latín confidere, que a la vez deriva de fiducia, vocablo que traducido al español significa "tener fe" en alguien o en algo. Este concepto simboliza la idea de "creer" y "esperar" con firmeza el advenimiento de un acontecimiento previamente imaginado.

Hecho esta introducción desde el punto de vista conceptual y etimológico se procederá reglones seguidos, una vez expuesto el diseño metodológico, con las diferentes concepciones de Confianza legítima, como una forma de confianza frente a la actuación de las autoridades publica y sus comportamientos sostenidos $y$ lineales en el tiempo. 


\section{Método.}

El artículo de que se acomete se encuentra dispuesto metodológicamente a partir de un enfoque de carácter cualitativo, para lo cual asimismo se hace uso de un nivel de investigación de contenido descriptivo. Por otra parte el método empleado fue deductivo, y el paradigma de investigación que se utilizó para su desarrollo fue el histórico hermenéutico. .

\section{Resultados y discusiones.}

Desde el punto de vista jurídico, la confianza legítima puede ser entendida como el principio encaminado a la protección a situaciones de carácter particular y no necesariamente a actos particulares, de manera que de disposiciones generales pueden tener origen derechos o situaciones jurídicas concretas. (Quintero,2003)

De acuerdo a otras concepciones el principio de confianza legitima, supone un amparo que debe dar el juez al ciudadano, frente a una Administración Pública que ha venido actuando de una determinada manera, y que repentinamente modifica su comportamiento o forma de decidir, rompiendo la confianza del ciudadano en que la administración seguiría actuando como lo hacía originariamente bajo circunstancias políticas, sociales o económicas similares.( Bermúdez, 2006 citado por Sarmiento 2008) 
El tratadista Bermúdez Soto (2006) explica el origen de esta definición en el derecho alemán, exponiendo, que el principio de confianza legítima, esencialmente, se vulnera en aquellos cambios sorpresivos de normas que afectan expectativas legítimamente creadas.

La jurisprudencia de la Corte Constitucional ha establecido que el principio de la confianza legítima consiste en una proyección de la buena fe que debe gobernar la relación entre las autoridades y los particulares, partiendo de la necesidad que tienen los administrados de ser protegidos frente a actos arbitrarios, repentinos, improvisados o similares por parte del Estado (T- 472-09). Igualmente, ha señalado que este principio propende por la protección de los particulares para que no sean vulneradas las expectativas fundadas que se habían hecho sobre la base de acciones $u$ omisiones estatales prolongadas en el tiempo, y consentido expresa o tácitamente por la administración ya sea que se trate de comportamientos activos o pasivos, regulación legal o interpretación normativa.

El supremo tribunal constitucional colombiano en un numero variado de fallos ( T-398 de 1997, T-576 de 1998 y SU 260 de 1998) ha establecido que este principio está encaminado a proteger al administrado y al ciudadano frente a cambios bruscos, abruptos e intempestivos efectuados por la administración. Se hace referencia a situaciones en las cuales el administrado no tiene realmente un derecho adquirido, dado que su situación jurídica puede ser modificada por las autoridades. Sin embargo, si la persona tiene razones objetivas para confiar en la durabilidad de la regulación, y el cambio súbito de la misma altera de manera sensible su situación, entonces el principio de la confianza legítima la protege. En estos casos, con ocasión de la buena fe (CP art. 83), el Estado debe brindar al afectado tiempo y medios que le permitan adaptarse a la nueva situación. Eso ocurre, verbi gracia, cuando una autoridad decide súbitamente prohibir una actividad que antes se encontraba permitida, por cuanto en ese evento, es deber del Estado permitir que el afectado pueda enfrentar ese cambio de política. 
En la sentencia C-131 de 2004 la Corte expreso que la confianza legítima consiste en que el ciudadano debe poder evolucionar en un medio jurídico estable y previsible en el cual pueda confiar. Se trata, que el particular debe ser protegido frente a cambios bruscos e inesperados efectuados por las autoridades públicas. En tal sentido, no se trata de amparar situaciones en las cuales el administrado sea titular de un derecho adquirido, es decir, se trata de una mera expectativa en que una determinada situación de hecho o regulación jurídica no serán modificadas intempestivamente.

Cuando se aplica el principio de confianza legitima lo que se busca es ofrecer un amparo jurídico a las expectativas razonables ciertas y fundadas que pueden refugiar a los administrados, con lo que refiere a la estabilidad o protección futura de carácter particular y concreto cuando estas han sido toleradas por el mismo estado. En ese sentido, los ciudadanos que abrigan la confianza justificada de que sus expectativas y esperanzas no van a ser objeto de frustración, modificación o alteración, no tienen por qué resultar defraudados, sorprendidos $\mathrm{o}$ asaltados en su buena fe como consecuencia del cambio inesperado de los ofrecimientos, promesas, criterios y políticas previamente expresados o como resultado del actuar contradictorio y desleal de las autoridades que a última hora deciden modificar la orientación y el sentido de decisiones y posturas suyas adoptadas anteriormente.( Coviello, 2004).

\section{Principio de confianza legítima y el derecho colectivo al espacio publico}

El principio de protección de la confianza legítima se aplica en aquellos casos en las cuales el Estado defrauda de manera inesperada la expectativas legitimas de los administrados, fundadas de manera razonable en actos, omisiones o declaraciones de las propias autoridades, con ocasión del cambio 
Vol.8, No 1. Diciembre de 2016 pp. 83-93

intempestivo de las regulaciones vigentes, el rompimiento de promesas $\mathrm{u}$ ofrecimientos formalmente efectuados, la terminación anticipada de procedimientos administrativos en trámite, el cambio de criterios y políticas, la modificación de las condiciones establecidas para el ejercicio de determinados derechos o el desconocimiento de las situaciones jurídicas particulares y concretas que han sido creadas, incluidas, toleradas o propiciadas por el propio Estado. Se protege tanto los derechos adquiridos, los derechos aparentes y las meras expectativas

Un caso particular y uno de los más recurrentes y conocido es el del ocupación de las calles y andenes por parte de vendedores y comerciantes estacionarios, que han ejercido esa actividad de manera prolongada y sostenida en el tiempo con la permisividad, conocimiento y tolerancia de la administración, incluso con la legitimidad del resto de la ciudadanía que satisface necesidades y se beneficia a través de esta actividad. Ahora bien, en cuanto a este asunto concreto, Según la sentencia C 601 de 1999 El principio de la confianza legítima, puede definirse como el mecanismo para conciliar, de un lado el interés general que se concreta en el deber de la administración de conservar y preservar el espacio público y, de otro lado, los derechos al trabajo e igualdad de las personas que ejercen el comercio informal.

En este sentido se genera un conflicto jurídico en el cual se enfrentan el interés general frente al particular, por un lado están los derechos fundamentales del trabajo y la igualdad y por otro lado el interés general en el cual está el desarrollo del estado, una de los sentencias que vela por el interés general es la T-617/95 la cual afirma que El espacio público y los bienes de uso público deben ser protegidos y al hacerlo el funcionario policivo cumple con su deber y por lo mismo su conducta es legítima y la orden que da de desalojo a quienes lo ocupan tiene la obligatoriedad propia del acto administrativo. La organización administrativa del Estado reposa sobre el principio del interés general. Es claro 
que la contraposición entre los intereses puramente particulares de los individuos aisladamente considerados, y los intereses generales, ha de resolverse necesariamente a favor de los intereses generales, pues lo colectivo debe primar sobre lo individual, y lo público sobre lo privado. El principio del interés general a su vez determina el contenido y campo de aplicación del principio de la confianza legítima. Pues en él, la confianza legítima encuentra su más claro límite. El principio de la confianza legítima encuentra un límite en su contenido y alcance que es dado por Principio del Interés General.

De igual manera hay muchas sentencias en las cuales los particulares demandan al estado alegando que se les están violando un derecho fundamental y que se les están devastando unas expectativas las cuales han venido trazándose a lo largo de su desempeño laboral el cual al momento de ser desalojados se estarán cercenando.

El principio de protección de la confianza legítima no es más que una transmutación de la teoría de los actos propios, la cual ha sido reformulada en el marco del derecho público, con la finalidad de garantizar la cabal aplicación de los principios, valores y normas que integran el Estado social de derecho, tales como la buena fe, la seguridad jurídica, la equidad y la justicia y para contrarrestar el ejercicio arbitrario del poder por parte de las autoridades públicas.( Valbuena Hernández G, 2008)

"los derechos casi nunca son absolutos: la mayoría son limitados en su extensión y están sometidos para su ejercicio a condiciones diversas. Cuando se sale de estos límites o no se observan estas condiciones, uno se desenvuelve, en realidad, sin derechos" de allí surge el axioma según el cual el derecho cesa donde el abuso comienza y un derecho termina en donde empieza el derecho de los demás. Esta es otra de las teorías que nos definen la confianza legítima según el tratadista Marcel Planiol 


\section{Conclusiones.}

Para concluir se trae a colación el caso de los vendedores ambulantes o del comercio informal, en el que se presenta una tensión entre el derecho al trabajo y el espacio público, que si bien se resuelve en favor del interés general determinando que estos deben desocupar el espacio público, en virtud del principio de confianza legítima se ha ordenado a la administración que asumiera una serie de medidas tendientes a procurar la reubicación de los mismos, lo cual les garantiza en debida forma su derecho al trabajo, sin desconocer el derecho de todos al espacio público.

Los organismos estatales en sus actuaciones están obligados a procurar el bienestar y el respeto de los derechos de la comunidad en general, no obstante el principal límite de la confianza legítima radica en el interés general y así quedó plasmado en la Sentencia T-617 de 1995, en los siguientes términos

Así mismo, de esta prescripción no se puede concluir necesariamente la persistencia sin mutaciones de las relaciones jurídicas que generan expectativas para los administrados, puesto que el principio está enfocado a la protección de la expectativa misma y no es loable pensar que la confianza legítima es una cláusula abierta que pueda traducirse en indemnizaciones y resarcimientos. La interpretación del precepto de la confianza legítima debe hacerse bajo el entendido de que no aplica sobre derechos adquiridos, sino de situaciones jurídicas susceptibles de modificación, puesto que respecto de los derechos adquiridos el ordenamiento jurídico contempla mecanismos específicos de protección. 
De lo desarrollado podemos afirmar que el principio de confianza legítima es un mecanismo de protección a las expectativas trazadas, y que si bien el estado tiene derecho y autoridad sobre el espacio público y que siempre prima el interés colectivo sobre el particular, también se debe brindar a los administrados una garantía que le permita desarrollarse sin que genere daños y perjuicios de gran magnitud.

Por tal razón las soluciones a este conflicto jurídico serian primero se compensar la confianza defraudada teniendo en cuenta que los intereses privados del afectado deben ceder ante el interés general o se dictan, por el contrario medidas encabezadas a garantizar su mantenimiento o a restablecer la situación que fue objeto de modificaciones. 


\section{Referencias.}

Agudelo Ibáñez, S., \& Calderón Ortega, M. (2016). Responsabilidad patrimonial del Estado colombiano por actos de reforma constitucional. Justicia, 21(29), 99-118. https://doi.org/10.17081/just.21.29.1236

Anderson, M. (2013). Testimonios de mujeres cubanas: Feminismo y afrocubanidad en tres textos de Daisy Rubiera Castillo. Cuadernos de Literatura del Caribe e Hispanoamérica, $\mathrm{N}^{\circ} .17$.

Arrieta, I. (2013). 'la construcción del ethos en el discurso político: un caso de legitimación y poder', en: cuadernos de literatura del caribe e hispanoamérica, no.19. Pp.13-35. Http://investigaciones.uniatlantico.edu.co/revistas/index.php/cuadernos_literatura/article/view/124 $8 / 874$

Balcarce, F. I. (2014). DERECHO PENAL Y NEUROCIENCIA: APROXIMACIONES. Revista LEGEM, 2(1), 81-93. Retrieved from http://investigaciones.uniatlantico.edu.co/revistas/index.php/legin/article/ view/1172

Bermúdez,J. (2006) El principio de confianza legítima en la actuación de la administración como límite a la potestad invalidatoria. Rev. Derecho (Valdivia), vol. 18, ํㅜ 2, pp. 83-105, en: http://www.scielo.cl/scielo.php?script=sci_arttext\&pid=S071809502005000200004\&lng=es\&nrm=iso. (Consultado el 27 de abril 2006) 
Berrocal Durán, J. (2016). Igualdad material de las partes en el proceso laboral:

Vol.8, No 1. Diciembre de 2016 pp. 83-93

audiencias, conciliación y primera de trámite. Justicia, 21(30), 122-131. https://doi.org/10.17081/just.21.30.1354

Caicedo Pérez, R. (2015). El derecho a huelga en Colombia: un sofisma. Legem, vol 2. Num 2., 87-100.

Carbonell, E. (2015). Apuntes de derecho concursal latinoamericano Colombia, Perú, México y Brasil. Revista LEGEM, 2(2), 11-35.

Coviello, P. J. (2004). La protección de la confianza del administrado. Lexis NexisC-478 de 1998,

Díez, Adriano (2014). El estudio de la migración internacional del retorno en Colombia. Una revisión bibliográfica sobre el estado actual. Revista Amauta. $\quad$ № 24: 23- $39 . \quad$ Recuperado de:http://investigaciones.uniatlantico.edu.co/revistas/index.php/Amauta/a rticle/view/1065

Fandiño Barrios, Y. (2014). La otredad y la discriminación de géneros. Advocatus, 23, 49-57.

Galettini, A. (2013). Más allá de la paradoja espacial: Otra manera de pensar la diáspora. Análisis de The Fat Black Woman's Poems, de Grace Nichols. Cuadernos de Literatura del Caribe e Hispanoamérica, N․ 17.

Mosquera Rentería, J. (2015). Derechos de las minorías sexuales: retos contemporáneos de la resocialización. Justicia, 20(28), 121-138. https://doi.org/10.17081/just.20.28.1044 
Orfale, R. N. (2014). Descentralización, participación ciudadana y gobierno local en Colombia. Advocatus, 22(22), 25-40.

Osorio Gutiérrez, M. (2015). Establecimiento de comercio en relación con los hosting web. Advocatus, (24), 67-77. https://doi.org/10.18041/01240102/advocatus.24.984

Planiol, M (2005) Tratado practico de derecho civil francés

Pórtela, J. (2015). Construcción del consenso moral del consenso y ley natural. Justicia, 20(28), 32-55. https://doi.org/10.17081/just.20.28.1033

Quintero, (2003) La tutela y la revocación de los actos administrativos, Revista Tutela, Acciones Populares y de Cumplimiento, no 29, tomo IV..

Reales Vega, R., de Castro Marriaga, D., \& Arcón, D. (2014). Percepción del agua como derecho fundamental: los efectos producidos por la prestación del servicio de agua potable en los habitantes del municipio de santa lucían, atlántico. Justicia, 19(26), 69-80. https://doi.org/10.17081/just.19.26.825

Rinvera García, Christian Geovany y Mondéjar Rodríguez, Juan. (2014): "La lectura crítica como habilidad investigativa en estudiantes universitarios". En: Revista Amauta. No.23, p.163-176.

Sarmiento, J.P. (2008) La vulneración a la confianza legítima ¿una situación jurídica generadora de responsabilidad del estado legislador?. Bogotá D.C: revista Vnivesitas.

En 
Vol.8, No 1. Diciembre de 2016 pp. 83-93

http://www.javeriana.edu.co/juridicas/pub_rev/documents/4Sarmiento(co nsultado el 12 de septiembre de 2011)

Sentencia C-131 de 2004, Corte Constitucional Colombiana.

Sentencia SU 260 de 1998, Corte Constitucional Colombiana.

Sentencia T-398 de 1997, Corte Constitucional Colombiana.

Sentencia T-472 de 2009, Corte Constitucional Colombiana.

Sentencia T-576 de 1998, Corte Constitucional Colombiana.

Soto, D. P. (2015). Francis Bacon y la Calumnia de America. Amauta, 1 - 16.

Valbuena, G (2008) La defraudación de la confianza legitima. Universidad Externado de Colombia.

Vega Arrieta, H. (2015). Aspectos dogmáticos y políticos criminales de la estructura general del delito en el sistema penal colombiano. Justicia, 20(27), $42-72$. https://doi.org/10.17081/just.20.27.806 